\title{
电针刺激大鼠脑内 $\mathrm{c}-\mathrm{fos}$ 原癌 基因表达加速*
}

周 岩 马青平 张志文 孙宇华 韩济生**

(北京医科大学神经科学研究中心, 北京 100083)

\section{关键词. 电针、原癌基因 e-fos 表因表达、分子杂交、免疫细胞化学}

原癌基因 c-fos 的表达产物 Fos 蛋白是细胞核内的磷酸蛋白, 它可同 DNA 结合生成 DNA 结合蛋白复合物 ${ }^{\text {W }}$. 现已知多种刺激可引起 c-fos 基因和 Fos 蛋白在中枢神经系统 的相关该团内表达 ${ }^{[2-4]}$. 许多研究者认为, Fos 蛋白可能作为一种核内 “第三信使”分子, 通过 调节特异靶基因的表达而把细胞外刺激和长时程的细胞功能改变联系起来 ${ }^{\left[{ }^{3}\right.}$. 本工作应用转 移电泳吸印 (northern blot) 杂交和免疫细胞化学 (immunocytochemistry, ICC) 的方法观 察了电针刺激对原癌基因 c-fos 表达的影响.

\section{1 材料与方法}

\section{1 材料}

(1) 试剂: Random Primer Labeling Kit 为 Bio-Rad 公司产品; ssDNA, tRNA, BSA 购自华美生物工程公司; $\alpha-{ }^{32} \mathrm{p}-\mathrm{dATP}$ 购自 NEN 公司; 原癌基因 $\mathrm{c}-\mathrm{fos}$ 探针 ( $\mathrm{pFBJ} \mathrm{J}_{2}$ 提取, 酶切片段为 $5.8 \mathrm{~kb}$ ) 购自华美生物工程公司; 尼龙膜 (Hybrond-N) 为 Amersham 公司产 品; 蔗煻、多聚甲醛、二氨基联苯胺 (DAB) 为北京化工厂产品; 秋水仙碱为瑞士 Fluka 公司 产品; Triton X-100 为 Rohmmass 公司进口分装; CCK-8 抗血清为美国洪昭雄博士馈赠; 5-羟色胺抗血清为美国 INCSTAR 公司产品; Fos 蛋白抗血清为 Oncogene Science 公司产 品; 生物素标记羊抗兔 IgG 血清和 ABC 复合物为 Vector Labs 公司产品; 骞聚脱氧胸苷纤 维素基质 (P-L type7) 为 Sigma 公司产品.

(2) 动物为 200-250g Wistar 大鼠, 在双后肢相当于“足三里”和“三阴交”部位进针, 以 辐射热甩尾法测痛, 给予电针(频率 $15 \mathrm{~Hz}$, 恒流 $3 \mathrm{~mA}$, 波宽 $0.3 \mathrm{~ms}$ ) 再测痛, 与电针前的基础 痛阈相比求得痛阈变化百分数. 持续电针 $1-8 \mathrm{~h}$, 分别于 $1,2,4,6,7$ 和 $8 \mathrm{~h}$ 末停止电针, 迅 速断头取脑, 对照组只插针 $0.5 \mathrm{~h}$ 不给电刺激. 脑组织去除皮层和小脑, 置液氮中冷冻保存至 RNA 提取. 取电针 $2 \mathrm{~h}$ 大鼠, 迅速灌流固定, 取脑切片进行 ICC 实验, 该对照组只插针 $2 \mathrm{~h}$ 不 给电刺激.

\section{2 方法}

1992-05-27 收稿，1992-10-04 收修改稿.

* 国家自然科学基金及 NIDA grant 资助项目.

***通讯联系人. 


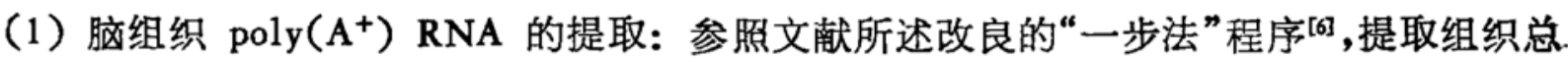
RNA, 再经窒聚 $(\mathrm{dT})$ 纤维素柱, 收集 poly $\left(\mathrm{A}^{+}\right) \mathrm{RNA}^{[n]}$, 然后溶于 $1 \times \mathrm{TE}$ 溶液, $\mathrm{OD}_{260} /$ $\mathrm{OD}_{250} \geqslant 1.80$, 计算含量.

(2) c-fos cDNA 探针的制备: 按 Random Primer Labeling Kit 提供的方案制备探 针, 标记率为 $50 \%$, 特异比活 $10^{5} \mathrm{dpm} / \mathrm{ng}$ 探针.

(3) 转移电泳吸印 ${ }^{[7}: 5 \mu \mathrm{g} p \operatorname{poly}\left(\mathrm{A}^{+}\right) \mathrm{RNA}$ 样品经变性处理后, 在 $1 \%$ 琼脂糖 $/ 2.2 \mathrm{~mol} / \mathrm{L}$ 甲醛变性电泳后,切下总 RNA 对照胶, 澳乙锭染色, 记录 $18 \mathrm{~s}$ 和 $28 \mathrm{~s}$ RNA 的迁移距离. 将 样品胶中 poly $\left(\mathrm{A}^{+}\right)$RNA 用 $10 \times \mathrm{SSC}$ 溶液被动吸印到尼龙膜上. 于 $80^{\circ} \mathrm{C}$ 烤 $2 \mathrm{~h}$, 固定 RNA.

（4）预杂交、杂交及杂交后漂洗：程序见文献 [1]. 在 $42^{\circ} \mathrm{C}$ 预杂交过夜后, 加人变性探针 (每毫升杂交液 $20 \mathrm{ng}$ 探针)， $42^{\circ} \mathrm{C}$ 杂交 $24 \mathrm{~h}$. 用 $1 \times S S C / 0.1 \%$ SDS 室温漂洗 2 次 $(2 \times 30$ $\min$ ), 再用 $0.1 \times \mathrm{SSC} / 0.1 \% \mathrm{SDS}$ 漂洗 $30 \mathrm{~min}$. 杂交膜于 $-70^{\circ} \mathrm{C}$ 曝光 2 天.

(5) ABC 法免疫细胞化学 ${ }^{[8]}$ : 按常规进行大鼠组织灌流、固定、切片 $(30 \mu \mathrm{m})$. 为显示肽 类神经元胞体, 实验前 $36 \mathrm{~h}$ 侧脑室注射秋水仙碱 $(100-200 \mu \mathrm{g} / 15 \mu \mathrm{l})$. 免疫反应按 $\mathrm{ABC}$ Kit 提供方法进行漂浮反应: 切片先置于 Fos 抗血清 (1:2000) 溶液中睬育 $48 \mathrm{~h}$, 用 $\mathrm{CoCl}_{2}$ 加 强的 DAB 显色; 切片再用 5-羟色胺抗血清 (1:8000) 或 CCK-8 抗血清 (1:5000) 摡育 48h, 用 $\mathrm{DAB}$ 显色后, 脱水封片. 对照试验采用: 在反应步骤中以 PBS 睬育缓冲液代替 Fos 抗 血清; 用人工合成的 Fos 蛋白肽段(氨基端 4-17 氨基酸残基)预先慨育吸收 Fos 抗血清,再 孵育切片. 以上两种对照试验中, 都无特异阳性染色.

(6) 统计方法: 组织学统计采用 $\chi^{2}$ 检验.

\section{2 结果 和讨 论}

c-fos 的 Northern 杂交放射自显影见图 1, 在分子量约 $2.2 \mathrm{~kb}$ 处有明显杂交带. 对照组 大鼠(1)脑组织只有很弱的杂交带, 电针 $1 \mathrm{~h}$ (3) 杂交信号明显增强, $2 \mathrm{~h}(4)$ 达高峰, 4-7h(5, $6,7)$ 逐渐减弱, $8 \mathrm{~h}(8)$ 基本恢复到对照组水平. 阴性对照 肝组织 (2) 未见阳性杂交带. 该实验每组取大鼠脑组织一 个,重复 3 次. 上述结果表明, 电针刺激 c-fos 基因表达迅 速增加 (于 $1 \mathrm{~h}$ ), 在 $2 \mathrm{~h}$ 达高峰, 然后逐渐恢复正常.

为观察电针刺激中枢参与痛调制的核团的 CCK 神经 元和 5-羟色胺神经元内是否有 Fos 蛋白表达, 采用 ICC 双重染色方法, Fos 蛋白位于细胞核, 用 $\mathrm{CoCl}_{2}$ 加强的 $\mathrm{DAB}$ 染色呈黑色; CCK 和 5-楼色胺位于胞质呈棕色. 对照组大 鼠中脑腹侧被盖区（ventral tegmental area, VTA）有密 集分布的 CCK 神经元, 未见 Fos 阳性染色(图 2(a)), 电

图 1 转移电泳吸印杂交放射自显影

1 为对照组, 2 为大鼠肝组织. $3-8$ 分别为电针刺激 $1,2,4,6,7$ 和 $8 \mathrm{~h}$
钎后 VTA 的 CCK 神经元中有大量 Fos/CCK 双标纪胞 (图 2(b) 和 (c), 随机抽取每组动物 $(n=5)$ 的 5 张切 片的统计结果为: 对照组 VTA 中未见 Fos/CCK 双染细 胞; 电针组 Fos/CCK 双染细胞占 VTA 中 CCK 细胞的 $58.9 \%$, 有非常显著的增加 ( $\chi^{2}$ 检 留, $p<0.001$ ). 对照组大鼠中缝背核 (nucleus raphe dersalis, NRD) 有大量的 5-差色胺 


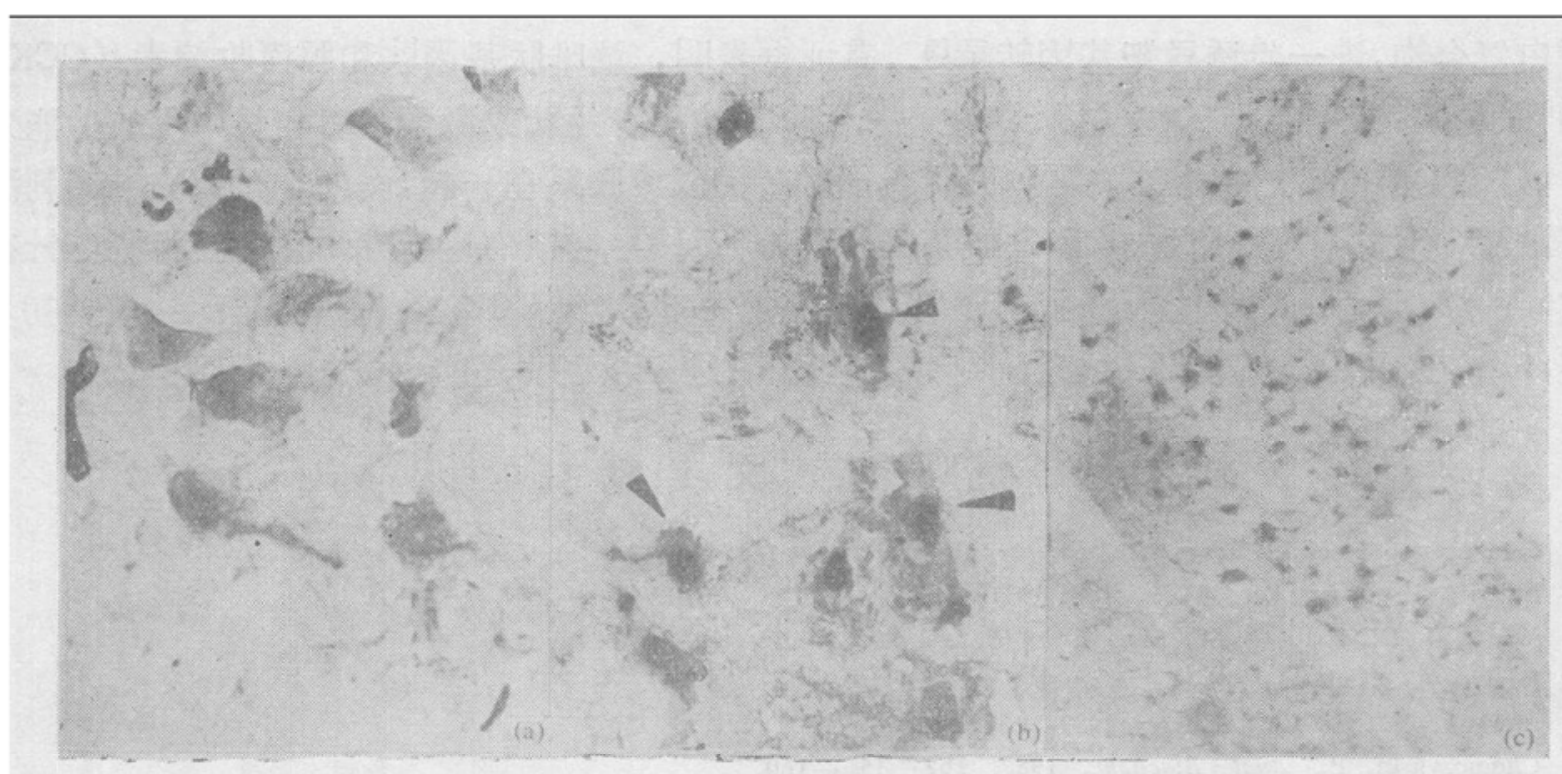

图 2

对照组 (a) VTA 内未见 Fos/CCK 双标神经元; 电针组 (b) VTA 可见 Fos/CCK 双标神经元(箭头所指) $(\times 24)$; 电针组 (c) VTA 的低倍镜 $(\times 60)$

神经元和少量的 Fos $/ 5$-羟色胺双染细胞 (占 10.2\%) (图 3(a)), 电针组 NRD 中 Fos/5-羟 色胺双染细胞显著增加, 为 $28.7 \%$ ( $X^{2}$ 检验, $p<0.01$ ) (图 3(b)). 结果表明, 电针刺激使 中枢与痛调制有关核团的 CCK 和 5-羟色胺神经元次 c-fos 基因表达加速.



图 3

对照组 (a) NRD 内只见少量 Fos/5-羟色胺双标神经元; 电针组 (b) NRD 内可见较多 Fos $/ 5$ - 柽色胺双标神经元(箭头所指) $(\times 140)$

目前对 c-fos 原癌基因的生理功能的研究愈来愈引起人们的重视, 已知伤害性刺激 ${ }^{[2]}$ 、㾈 㾁发作 ${ }^{[3]}$ 和光刺激等都可引起脑内 $\mathrm{c}$-fos 基因快速短暂的表达, 因此又称该种基因为早期快 速反应基因 (immediate-early gene). 本实验观察到在电针刺激的情况下, c-fos mRNA 和 Fos 蛋白在 1-2h 表达明显增加. Fos 蛋白与 c-jun 基因的表达产物 Jun 蛋白结合成双聚 
体蛋白复合物,进一步诱导靶基因转录 ${ }^{[]}$. 有证据表明, 脑啡肽基因 ${ }^{[4]}$ 和胆豪收缩素 (CCK) 基因 ${ }^{[9]}$ 可能是 Fos 调节的靶基因, 这些靶基因再表达出神经肽或激素, 参与长时程的功能变 化. 可以认为 Fos 把初始的突触刺激同长期的基因改变联系在一起, 例如长时间的电针刺激 能够激活中枢抗阿片系统 (如 CCK, 血管紧张素等)而使电针镇痛逐渐减弱, 出现耐受. 电针在 短时间内激活 c-fos 基因表达,那么是否 Fos 能进一步调节 CCK 的基因表这呢? 我们初步 证实 Fos 在 VTA 的 CCK 神经元中有表达,要想进一步证明还需更多的生化证据.

\section{参考文献}

[1] Sambucetti, L. C., Curran, T., Science, 1986, 234: 1417-1419.

[2] Bullitt, E., Brain Res., 1989, 493: 391-397.

[ 3 ] White, J. D., Gall, C. M., Mol. Brain Res., 1987, 3: 21-29.

[4] Draisci, G., Iadarola, M. J., Mol. Brain Res., 1989, 6: 31-37.

[5] Morgan, J. I. et al., Science, 1987, 237: 192-194.

[6] Chomczynski, P., Anal. Biochem., 1987, 162: 156-160.

[7] Maniatis, T. et al., Molecular Cloning: A Laboratory Manual, Cold Spring Harbor Laboratory, 1989.

[8] Hsu, S. M. et al., J Histochem. Cytochem., 1981, 29: 577-580.

I 91 Haun, R. S., Dixon, J. E., J. Biol. Chem., 1990, 265: 15455-15463. 